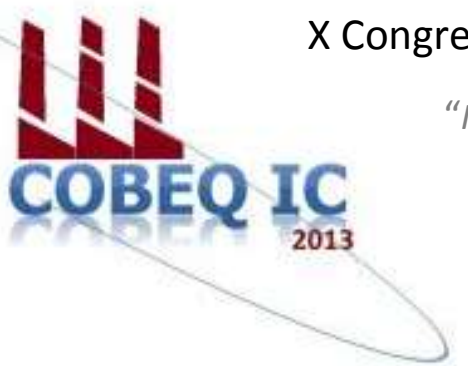

"Influência da pesquisa em Engenharia Química no desenvolvimento tecnológico e industrial brasileiro"

Universidade Federal Rural do Rio de Janeiro Universidade Severino Sombra Vassouras - RJ-Brasil

\title{
INFLUÊNCIA DA CONCENTRAÇÃO INICIAL DE CROMO HEXAVALENTE NA REMOÇÃO DE CROMO EM BIORREATORES HÍBRIDOS SEQUENCIAIS
}

\author{
F.A Lima ${ }^{1}$; G.M Alves ${ }^{2}$; C.A. Brandão ${ }^{3}$, M.M. de Resende ${ }^{4}$; V.L Cardoso ${ }^{4}$ \\ (1) Bolsista de Iniciação Científica - PIBIC/Fapemig/UFU; \\ ${ }^{(2)}$ Bolsista - PIBIT IT-CNPq \\ ${ }^{(3)}$ Bolsista do programa de pós-graduação em Engenharia Química PPGEC/CNPQ; \\ ${ }^{(4)}$ Docentes - FEQ/UFU
}

Faculdade de Engenharia Química, Universidade Federal de Uberlândia. Av João Naves de Ávila, 2121, Bloco 1K, Campus Santa Mônica, Uberlândia - MG, CEP 38408-100 e-mail: mresende@feq.ufu.br

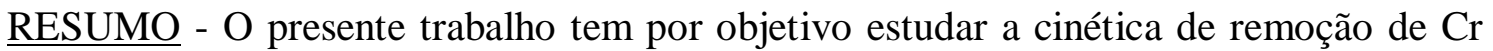
(VI) e Cromo Total em um sistema de biorreatores híbridos sequenciais, sem aeração e com aeração intermitente, utilizando cultura mista de micro-organismos, previamente adaptada ao cromo. Foram realizados dois ensaios cinéticos com meio sintético (afluente) contendo concentrações iniciais de $\mathrm{Cr}$ (VI) de 80 e $120 \mathrm{mg} / \mathrm{L}$, usando o dicromato de potássio $\left(\mathrm{K}_{2} \mathrm{Cr}_{2} \mathrm{O}_{7}\right)$ como fonte de cromo. Após cada ensaio, avaliou-se a remoção durante a regeneração do sistema, na qual foi utilizado o mesmo meio, porém sem cromo. A concentração de $\mathrm{Cr}$ (VI) foi determinada pelo método colorimétrico utilizando difenilcarbazida 3500-Cr D, conforme APHA (2005). A concentração de Cromo Total foi medida em Espectrofotômetro de absorção atômica AA-7000 Shimadzu. Para a cinética com concentração de $80 \mathrm{mg} / \mathrm{L}$ de Cr (VI), os resultados mostraram que após 600 horas de operação não ocorreu a saturação dos biorreatores, obtendo-se $87 \%$ de remoção global de Cr (VI) e $62 \%$ de Cromo Total. Para a cinética de $120 \mathrm{mg} / \mathrm{L}$, apenas o biorreator sem aeração atingiu a saturação, após 225 horas de operação. Nas regenerações, verificou-se que concentração de cromo na saída do sistema se tornou praticamente nula após 48 horas de operação.
\end{abstract}

Palavras chave: cultura mista, biossorção, bioacumulação.

\section{INTRODUÇÃO}

O cromo é encontrado em noves estados de oxidação, variando de -2 até +6 , mas somente os estados trivalante e hexavalente são suficientemente estáveis para ocorrerem no ambiente (DERMOU et al., 2007). O Cr (III), dentro de uma estreita faixa 
de concentração, é uma espécie essencial para os mamíferos, atuando nos mecanismos de manutenção da glicose, lipídeos e proteínas (MONTEIRO et al., 2002). Por sua vez, o $\mathrm{Cr}$ (VI) é conhecido por seus efeitos tóxicos nos seres humanos quando inalado, devido à suas propriedades carcinogênicas e mutagênicas, além de ser uma substância acumulativa no organismo dos seres vivos (DERMOU et al., 2007).

Os mecanismos pelos quais os microorganismos interagem com metais tóxicos, promovendo sua remoção e/ recuperação, são a biossorção na superfície, a bioacumulação (intracelular ou extracelular/precipitação) e a redução biológica (GADD 1990; SRINATH et al, 2002).

A biossorção é resultado da interação eletrostática e também da formação de complexos entre íons metálicos e grupos funcionais presentes nas biomassas, quando estas possuem afinidade química pelo metal. Modificações químicas que possuem a finalidade de introduzir grupos funcionais na estrutura desses adsorventes podem aumentar a capacidade de sorção (SANTOS et al, 2011).

O termo bioacumulação é definido como a captação de espécies metálicas através de processos que requerem atividade metabólica. . Neste processo o metal é captado por células vivas através de diferentes caminhos, como o transporte através da membrana celular, a síntese de proteínas intra e extracelulares com capacidade de formar ligação com metais, a precipitação extracelular e a formação de complexos com metabólitos da reação (RIZZO e LEITE, 2004).

Culturas bacterianas mistas podem promover a redução do $\mathrm{Cr}$ (VI) a $\mathrm{Cr}$ (III), sobre condições aeróbias e/ou anaeróbias. A redução de $\mathrm{Cr}$ (VI) por micro-organismos na presença de oxigênio ocorre, geralmente, em dois ou três passos, com o Cr (VI) sendo inicialmente reduzido para os estados intermediários $\mathrm{Cr}$ (V) e/ou Cr (IV) que são de curta duração, e a posterior redução para o $\mathrm{Cr}$ (III), que é termodinamicamente estável. Essa redução é geralmente, catalisada por enzimas solúveis (CHIRWA e WANG, 1997). Na ausência de oxigênio, o $\mathrm{Cr}$ (VI) pode servir como aceptor final de elétrons na cadeia respiratória de uma grande variedade de doadores de elétrons, como carboidratos, proteínas, gorduras e hidrogênio (CHEUNG e GU, 2007).

Poucos estudos sobre o uso de biorreatores híbridos para remoção de metais são encontrados na literatura. A maior parte dos trabalhos se referem a remoção de matéria orgânica e nitrogênio de efluentes com características de esgoto doméstico (WOLFF, 2005; METCALFF e EDDY, 2003).

Os biorreatores híbridos são caracterizados por conter biomassa fixa e em suspensão em um mesmo volume reacional. Nesse tipo de sistema são utilizados materiais suportes de elevada superfície específica para o crescimento bacteriano, visando agregar as vantagens do sistema de lodo ativado (biomassa floculada) e do biofilme (biomassa fixa) (WOLFF, 2005).

Sendo assim, o objetivo do presente trabalho foi avaliar o desempenho do sistema de tratamento constituído por biorreatores híbridos sequenciais, sem aeração e com aeração intermitente, na remoção de cromo de um meio sintético, utilizando cultura mista de micro-organismos originária de lodo industrial, como inóculo. Foram determinadas as curvas cinéticas de saturação e regeneração dos leitos em relação às concentrações de $\mathrm{Cr}$ (VI) e Cromo Total.

\section{METODOLOGIA}

\section{Preparação do inóculo}

Foram utilizadas amostras obtidas do lodo de uma indústria de curtume localizada na cidade de Franca (SP). Para o crescimento dos micro-organismos, colocou-se $60 \mathrm{~mL}$ de lodo em $200 \mathrm{~mL}$ de meio de cultura contendo: $\mathrm{NH}_{4} \mathrm{CL}(1 \mathrm{~g} / \mathrm{L}), \mathrm{MgSO}_{4} .7 \mathrm{H}_{2} \mathrm{O}(0,2 \mathrm{mg} / \mathrm{L})$, $\mathrm{FeSO}_{4} .7 \mathrm{H}_{2} \mathrm{O}(0,001 \mathrm{~g} / \mathrm{L}), \mathrm{CaCl}_{2}(0,001 \mathrm{~g} / \mathrm{L})$, $\mathrm{CH}_{3} \mathrm{COONa} .3 \quad \mathrm{H}_{2} \mathrm{O}(6,0 \mathrm{~g} / \mathrm{L}), \mathrm{K}_{2} \mathrm{HPO}_{4}(0,5$ $\mathrm{g} / \mathrm{L})$, extrato de levedura $(0,5 \mathrm{~g} / \mathrm{L})$. Os erlenmeyers contendo o meio de cultura e os micro-organismos foram mantidos em shaker sob agitação, a temperatura de $27 \pm 1^{\circ} \mathrm{C}$. O meio foi trocado ao fim do ciclo de 48 horas e por 90 dias realizaram-se cultivos sucessivos para o aumento da biomassa, procedendo-se na sequência à adaptação ao cromo, nas concentrações de 40 e $80 \mathrm{mg} / \mathrm{L}$, utilizando dicromato de potássio $\left(\mathrm{K}_{2} \mathrm{Cr}_{2} \mathrm{O}_{7}\right)$ como fonte 
de cromo hexavalente. Após 60 dias do período de adaptação ao cromo, obteve-se 15 litros de biomassa para serem usados como inóculo. Esse volume foi imediatamente introduzido nos biorreatores, por bombeamento, e permaneceram dentre destes por 30 dias, com a alimentação do meio de cultura, sem cromo, feita por seringas, com o propósito de garantir a fixação dos microorganismos ao material suporte para formação do biofilme. Nesse período, e durante os experimentos, utilizou-se aeração intermitente no segundo biorreator, devido à turbulência causada pelo fluxo de ar, o que dificulta a fixação dos micro-organismos no material suporte.

\section{Sistema Experimental Utilizado}

O sistema utilizado, em escala piloto, foi composto por um biorreator híbrido sem aeração seguido por outro com aeração intermitente, ambos operando com fluxo ascendente, com diâmetro de $16,5 \mathrm{~cm}$ e altura de $60 \mathrm{~cm}$, e volume total de 12,6 L cada. O material empregado para confecção dos biorreatores foram tubos de acrílico. Como material suporte, foram utilizadas partículas cilíndricas de polipropileno, com diâmetro de 3,5 $\mathrm{mm}$ (biorreator sem aeração), e anéis de silicone, com diâmetro de 11,20 mm (com aeração intermitente).

A Figura 1 descreve esquematicamente o sistema com os pontos de amostragem. O meio sintético (meio de cultura + cromo) foi bombeado diretamente do tanque de alimentação até o primeiro biorreator (sem aeração), a uma vazão de $4 \mathrm{~mL} / \mathrm{min}-0,25$ $\mathrm{L} / \mathrm{h}$, em pH neutro, o que corresponde a um tempo de detenção hidráulico (TDH) de 48 horas. Para o bombeamento do meio sintético, foi utilizada uma mangueira (diâmetro interno de 1,2 mm) acoplada à uma bomba peristáltica Watson Marlow, modelo 520S. Outra mangueira foi ligada ao topo deste biorreator para saída do efluente e posterior entrada no segundo biorreator (com aeração). No topo do biorreator aerado, uma mangueira foi ligada para a saída do efluente, assim como um dispositivo para fornecimento de ar comprimido, quatro vezes ao dia, a uma vazão de $20 \mathrm{~mL} / \mathrm{min}$. Uma mangueira para saída dos gases gerados, e outra para a saída do ar alimentado, foram instaladas no topo do biorreator sem aeração e do biorreator aerado, respectivamente. As amostras foram coletadas em três pontos distintos, indicados na Figura 1: entrada (ponto 1) e saída do biorreator sem aeração (ponto 2) e saída do aerado (ponto 3).

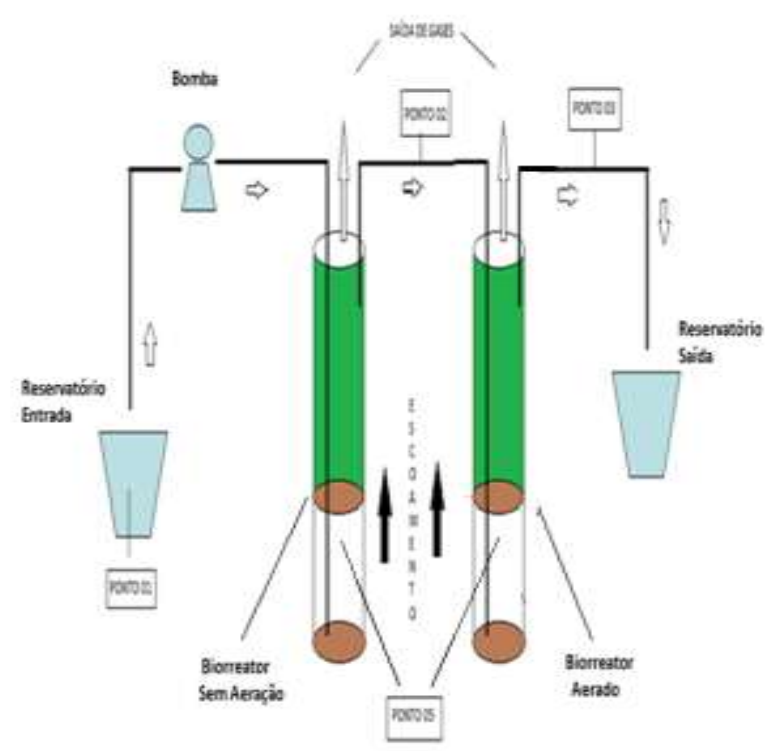

\section{Figura 1 - Representação esquemática do sistema indicando os pontos de coleta.}

\section{Curvas cinéticas de saturação e regeneração dos leitos}

Foram realizados dois ensaios cinéticos com o mesmo meio de cultura (afluente) contendo $\mathrm{Cr}$ (VI) nas concentrações iniciais de $80 \mathrm{mg} / \mathrm{L}$ e $120 \mathrm{mg} / \mathrm{L}$, respectivamente. Tais valores foram escolhidos por estarem na faixa de concentração de $\mathrm{Cr}$ (VI) geralmente encontrada em efluentes de curtume. Em todos os ensaios buscou-se atingir o tempo de saturação dos biorreatores, isto é, quando a concentração de cromo na saída dos mesmos se torna igual à concentração na entrada do sistema. No intervalo entre os ensaios cinéticos foi feita a regeneração dos biorreatores, utilizando-se o mesmo meio de cultura, porém sem cromo.

As eficiências de remoção dos biorreatores foram calculadas pelas Equações 1 a 3: 
Eficiência Reator $1(\%)=\frac{1}{\mathrm{~N}} * \sum \frac{(\mathrm{C} 1-\mathrm{Co})}{\mathrm{Co}}$

Eficiência Reator $2(\%)=\frac{1}{\mathrm{~N}} * \sum \frac{(\mathrm{C} 2-\mathrm{C} 1)}{\mathrm{C} 1}$

Eficiência Global $(\%)=\frac{1}{\mathrm{~N}} * \Sigma \frac{(\mathrm{C} 2-\mathrm{Co})}{\mathrm{Co}}$

Onde:

C1 = Concentração de cromo na saída do biorreator sem aeração, em cada ponto experimental;

C2 = Concentração de cromo na saída do biorreator aerado, em cada ponto experimental;

$\mathrm{C} 0$ = Concentração de cromo na entrada do sistema em cada ponto experimental;

$\mathrm{N}=$ número de pontos experimentais

\section{Métodos Analíticos}

A concentração de $\mathrm{Cr}$ (VI) foi determinada pelo método colorimétrico utilizando difenilcarbazida 3500-Cr D, conforme APHA (2005). A concentração de Cromo Total foi medida em Espectrofotômetro de absorção atômica AA-7000 Shimadzu. A análise dos Sólidos Voláteis em Suspensão (SSV) foi realizada pelo método dos sólidos fixos e voláteis inflamados a $550^{\circ} \mathrm{C}$, descrito por APHA (2005).

\section{RESULTADOS E DISCUSSÕES}

\section{Concentração inicial de 80 mg/L de Cr (VI)}

A concentração inicial de biomassa no biorreator sem aeração foi de $3500 \mathrm{mg} / \mathrm{L}$, enquanto que no biorreator aerado esta foi de $2500 \mathrm{mg} / \mathrm{L}$ de SSV. A concentração de SSV nos dois biorreatores diminuiu durante as 240 horas iniciais, chegando a $1140 \mathrm{mg} / \mathrm{L}$ no primeiro biorreator, e a $1500 \mathrm{mg} / \mathrm{L}$ no segundo biorreator, permanecendo, em média, próxima a estes valores até o final do experimento de saturação.

A Figura 2 mostra a cinética de remoção de Cr (VI) e Cromo Total, em 600 horas de operação do sistema. A concentração média de Cr (VI) na entrada do sistema foi de $77 \mathrm{mg} / \mathrm{L}$. Até 108 horas de experimento só houve presença significativa de $\mathrm{Cr}$ Total na saída do biorreator sem aeração, em torno de $27 \mathrm{mg} / \mathrm{L}$. A concentração de Cr (VI) na saída deste biorreator só começou a aumentar após 120 horas de operação. Já na saída do biorreator com aeração intermitente, a concentração de $\mathrm{Cr}$ Total começou a aumentar após 168 horas, e a de Cr (VI) após 264 horas, quando $\mathrm{o} 1^{\circ}$ biorreator já tendia a estabilização em relação a concentração de $\mathrm{Cr}$ Total. Após 360 horas, a concentração de Cr Total na saída do biorreator sem aeração tornou-se constante, em torno de $56 \mathrm{mg} / \mathrm{L}$, enquanto que a de $\mathrm{Cr}$ (VI) estabilizou-se por volta de $27 \mathrm{mg} / \mathrm{L}$, após 432 horas de operação. A concentração de $\mathrm{Cr}$ (VI) na saída do $2^{\circ}$ reator estabilizou-se em torno de $9 \mathrm{mg} / \mathrm{L}$, em 432 horas de funcionamento, ao mesmo tempo em que ocorreu a estabilização da concentração de $\mathrm{Cr}$ Total, por volta de $30 \mathrm{mg} / \mathrm{L}$. No entanto, constatou-se que após 600 horas os biorreatores não saturaram.

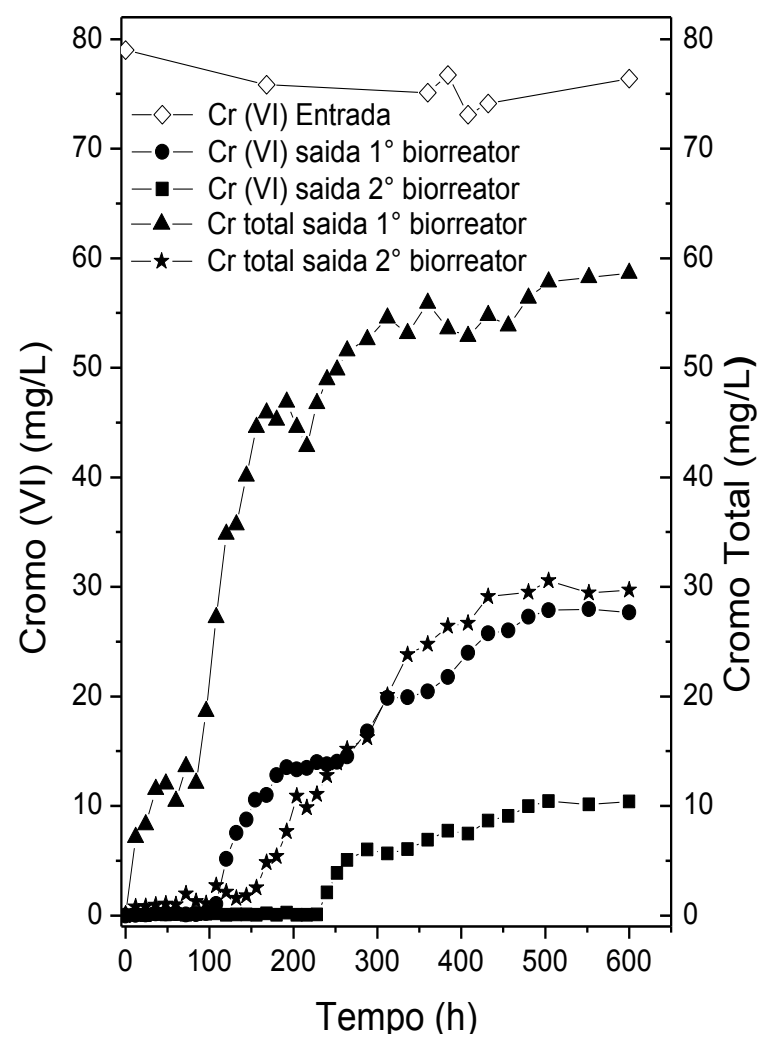

Figura 2 - Valores da concentração de $\mathbf{C r}$ (VI) e Cromo Total em relação ao tempo para a saída dos biorreatores durante a saturação $(80 \mathrm{mg} / \mathrm{L})$.

A eficiência global de remoção em 48 horas, o TDH adotado, foi de aproximadamente $100 \%$, tanto para o $\mathrm{Cr}$ (VI) 
quanto para o $\mathrm{Cr}$ total. Em 96 horas, o equivalente a dois TDH, o percentual de remoção global permaneceu praticamente $\mathrm{o}$ mesmo, mostrando que as concentrações de $\mathrm{Cr}$ (VI) e Cr Total, na saída do sistema, foram menores que $1 \mathrm{mg} / \mathrm{L}$, até esse instante. A eficiência global de remoção, após a estabilização do sistema (em 432 horas, aproximadamente), foi de $87 \%$ para o $\mathrm{Cr}$ (VI) e $62 \%$ para o Cr Total.

A Figura 3 mostra a concentração de cromo em função do tempo durante regeneração.

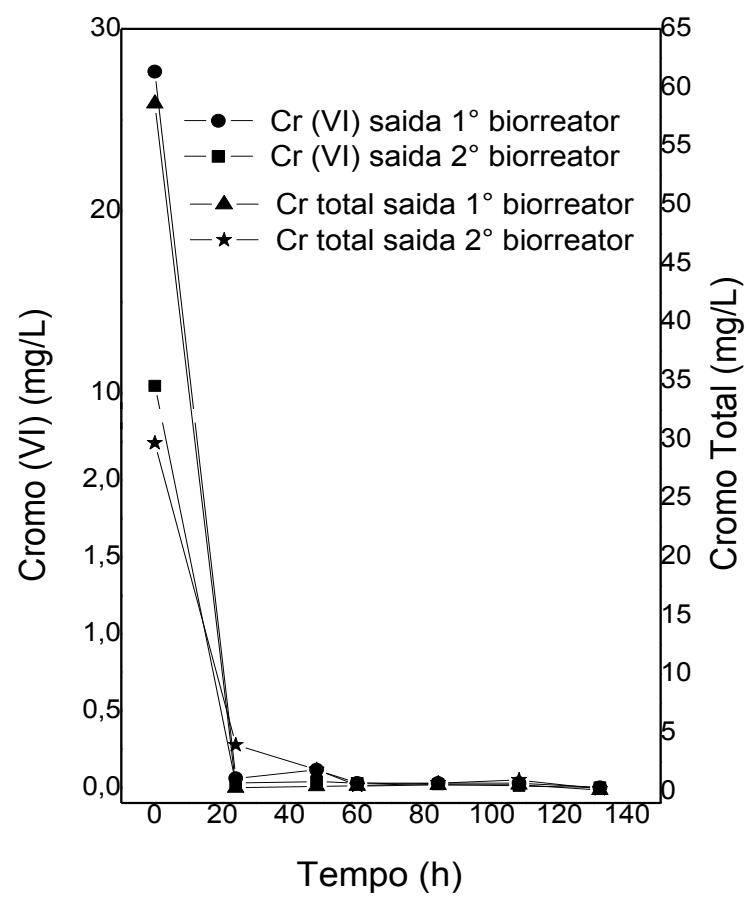

Figura 3 - Concentração de $\mathrm{Cr}$ (VI) e Cromo Total em relação ao tempo na saída dos biorreatores durante a regeneração $(80$ mg/L de Cr (VI)).

Após 24 horas de alimentação de meio de cultura sem cromo, os biorreatores passaram a liberar quantidades baixas de $\mathrm{Cr}$ (VI) e Cr Total $(<1 \mathrm{mg} / \mathrm{L})$, se tornando praticamente nulas logo após 48 horas de operação. A concentração de biomassa aumentou, chegando a $2500 \mathrm{mg} / \mathrm{L}$ no primeiro biorreator e a $2600 \mathrm{mg} / \mathrm{L}$ no segundo, após o final da regeneração, em 132 horas.

Utilizando um reator contínuo com biomassa em suspensão, sob condições aeróbias, Elangovan e Philip (2009) obtiveram 70-80\% de eficiência de redução Cr (VI) em
48 horas de processo, para uma concentração inicial de $20 \mathrm{mg} / \mathrm{L}$ de cromo hexavalente adicionada ao meio. No entanto, a eficiência de redução foi reduzida para $20 \%$, após 25 dias. A biomassa diminuiu nesse período, de uma concentração inicial de $2000 \mathrm{mg} / \mathrm{L}$ para $1100 \mathrm{mg} / \mathrm{L}$ de SSV. Dalcin (2009) obteve 70\% de remoção de $\mathrm{Cr}$ (VI) de um afluente sintético contendo $90 \mathrm{mg} / \mathrm{L}$ de $\mathrm{Cr}$ (VI), em 30 horas de operação, utilizando um filtro biológico de fluxo contínuo com cultura mista de microorganismos.

\section{Concentração inicial de $120 \mathrm{mg} / \mathrm{L}$ de $\mathrm{Cr}$ (VI)}

A concentração de SSV, nos dois biorreatores, decresceu nas 48 horas iniciais do experimento, aumentando após esse instante e permanecendo praticamente estável, em 2150 $\mathrm{mg} / \mathrm{L}$ no biorreator sem aeração e em 2560 $\mathrm{mg} / \mathrm{L}$ no biorreator aerado. Tal fato sugere a ocorrência de alterações no metabolismo celular e na microbiota, visando uma nova adaptação às condições do reator.

A Figura 4 mostra a cinética de remoção de Cr (VI) e Cromo Total, em 360 horas, utilizando uma concentração de 120 $\mathrm{mg} / \mathrm{L}$.

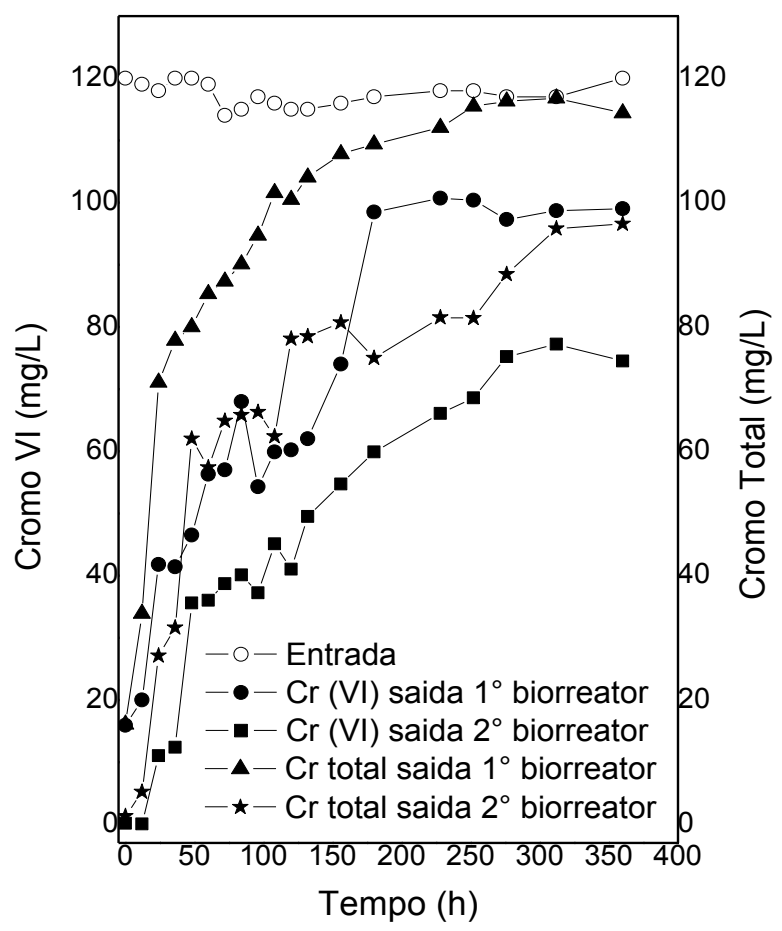

Figura 4 - Valores da concentração de $\mathrm{Cr}$ (VI) e Cromo Total em relação ao tempo para a saída dos biorreatores durante a saturação (120 mg/L). 
O biorreator sem aeração atingiu a saturação, em relação a concentração de Cromo Total, após 228 horas. A concentração média de Cr (VI) na entrada do sistema foi de $115 \mathrm{mg} / \mathrm{L}$. Após 180 horas de operação, verificou-se que a concentração de $\mathrm{Cr}$ Total na saída do biorreator sem aeração chegou a um valor médio de $116 \mathrm{mg} / \mathrm{L}$, indicando a saturação do mesmo. A concentração de $\mathrm{Cr}$ (VI) estabilizou a partir deste mesmo instante, em torno de $100 \mathrm{mg} / \mathrm{L}$. O biorreator aerado não chegou a atingir a saturação, sendo que as concentrações de $\mathrm{Cr}$ (VI) e de Cr Total, na saída deste, estabilizaram-se em torno de 75 $\mathrm{mg} / \mathrm{L}$ e $90 \mathrm{mg} / \mathrm{L}$, respectivamente, após 312 horas. Esse fato mostra que os microorganismos presentes no biorreator aerado continuaram a remover o cromo, mesmo recebendo uma maior carga do metal, devido à saturação do primeiro biorreator, mostrando uma vantagem de se trabalhar com os biorreatores em série.

Neste caso, a eficiência global de remoção no TDH (48 horas) foi de $70 \%$ para o $\mathrm{Cr}$ (VI) e de $48 \%$ para o $\mathrm{Cr}$ Total, valores inferiores aos encontrados na cinética de 80 $\mathrm{mg} / \mathrm{L}$ de Cr (VI), na qual a remoção foi de aproximadamente $100 \%$ para o tempo em questão. Esse fato era esperado devido ao aumento da concentração de cromo hexavalente adicionada. A eficiência global de remoção, após a estabilização do sistema, foi de $37,5 \%$ para o $\mathrm{Cr}$ (VI) e $25 \%$ para o Cromo Total.

$\mathrm{Na}$ regeneração, os biorreatores só passaram a liberar baixas quantidades de $\mathrm{Cr}$ (VI) e Cr Total $(<1 \mathrm{mg} / \mathrm{L})$, após 72 horas, três vezes o tempo necessário para a regeneração do sistema no experimento com $80 \mathrm{mg} / \mathrm{L}$ de $\mathrm{Cr}$ (VI). No entanto, a concentração de cromo remanescente no meio, neste caso, era maior. A concentração de SSV aumentou novamente, chegando a $2350 \mathrm{mg} / \mathrm{L}$ no biorreator sem aeração e a $2800 \mathrm{mg} / \mathrm{L}$ no biorreator aerado, ao término da regeneração. A Figura 5 mostra a regeneração dos leitos.

Leles (2010), utilizando um sistema constituído por um filtro anaeróbio seguido por um biofiltro aerado, com cultura mista de mesma origem da utilizada neste trabalho, não verificou a saturação em nenhum dos reatores, durante 168 horas de operação, para a concentração inicial de Cr (VI) de $120 \mathrm{mg} / \mathrm{L}$. A remoção de $\mathrm{Cr}$ (VI) e Cr total obtida, após estabilização do sistema, foi de $100 \%$, o que ocorreu após 142 horas.

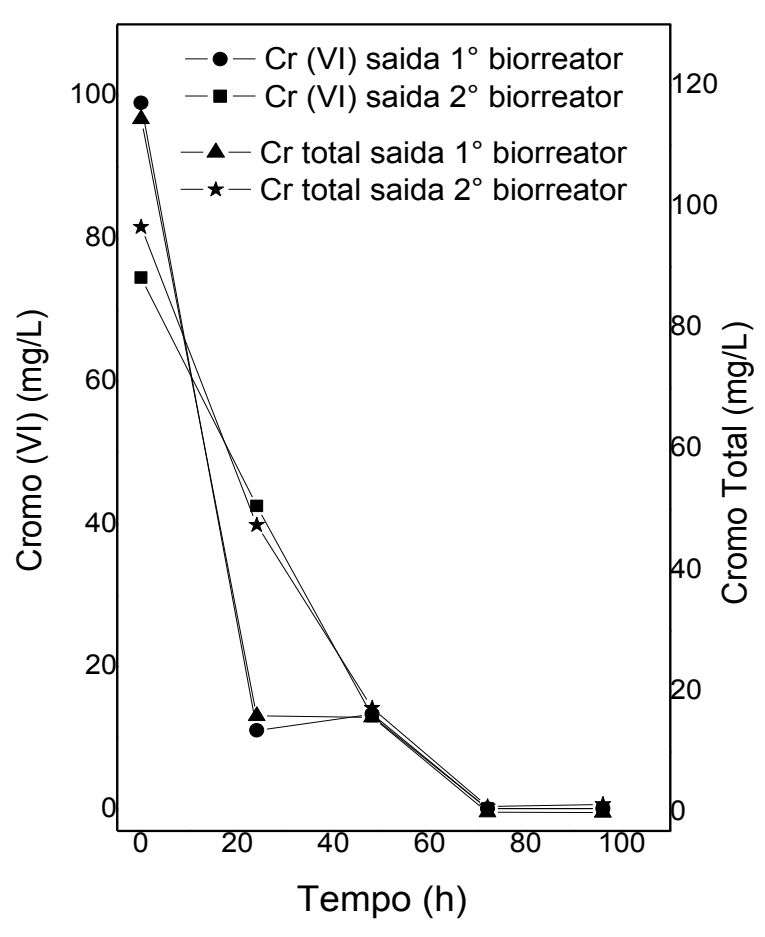

Figura 5 - Valores da concentração de $\mathbf{C r}$ (VI) e Cromo Total em relação ao tempo para a saída dos biorreatores durante a regeneração $(120 \mathrm{mg} / \mathrm{L})$.

\section{CONCLUSÃO}

Foi verificado que o percentual de remoção de cromo diminuiu de um experimento para o outro. Os principais fatores que podem ter levado a isso são o aumento da concentração de $\mathrm{Cr}$ (VI) no meio afluente ao sistema e o processo de acumulação do metal pelos micro-organismos, o que leva à diminuição da capacidade de remoção. $O$ fato de o sistema ter funcionado de forma contínua, sem reposição de células, fez com que a acumulação tenha sido mais acentuada a cada experimento. A acumulação pode ser intra ou extracelular e dependente do metabolismo (bioacumulaçao), ou independente deste, estando os íons metálicos depositados sobre a superfície celular tanto de células vivas quanto de mortas (biossorção). Com o decorrer do tempo, a grande quantidade de cromo 
depositada sobre as células (biossorvida) passa a produzir problemas difusionais graves no leito, impedindo que o $\mathrm{Cr}$ (VI) seja biossorvido, reduzindo o percentual de remoção.

Dessa forma, o cromo removido do meio sintético encontra-se dentro dos biorreatores, podendo estar biossorvido (provavelmente complexado) na membrana celular e no material suporte (biofilme), assim como em alguns produtos intermediários gerados no processo; bioacumulado no interior ou no exterior de células vivas, ou, ainda, precipitado no fundo dos biorreatores.

\section{REFERÊNCIAS}

APHA, Standard Methods for the examination of water \& wastewater (2005), 3500-Cr B. Colorimetric Method,. Washington, D.C, p.366, 2005.

CHEUNG, K.H., GU JI-DONG (2007), Mechanism of hexavalent chromium detoxification by microorganisms and bioremediation application potential: A review. International Biodeterioration e Biodegradation 59.

CHIRWA, E.M.N., WANG, Y (1997) Hexavalent chromium reduction by Bacilus $s p$. in a packed bed bioreactor. Environ. Sci. Technol. 31, p.1446-1451.

DALCIN, M, G (2009), Redução de cromo hexavalente em filtro biológico de fluxo continuo. Dissertação de Mestrado, Universidade Federal de Uberlândia, Uberlândia, MG, 98 pag.

DERMOU, E.,VELISSARIOU, A., XENOS, D., VAYENAS, D.V (2007), Biological removal of hexavalent chromium in trickling filters operating with different filter media types. Desalination 211, p.156-163.

ELANGOVAN, R., PHILIP, L., CHANDRARAL, K (2008), Hexavalent Chromium Reduction by Free and Immobilized Cell-free Extract of Arthrobacter rhombi-RE. Biochem Biotechnol.
GADD, G.M (1990), Fungi and Yeast for Metal Accumulation in Microbial Mineral Recovery. Environmental Biotechnology, H.L. Lehrlich, C.L. Bierley, Eds., McGraw Hill, p. 249-275.

LELES, D, M, A (2010), Uso de Biofiltros para remoção de cromo (VI). Dissertação de Mestrado, Universidade Federal de Uberlândia, Uberlândia, MG, 102 pag.

METCALF, EDDY (2003), Wastewater Engineering: treatment, disposal and reuse. New York: McGraw-Hill, 1334 pag.

MONTEIRO, M, I, C., FRAGA, I, C, S., Y, DE OLIVEIRA, A, V., N, M, M., RIBEIRO, S, H (2002), Determination of total chromium traces in tannery effluents by electrothermal atomic absorption spectrometry, flame atomic absorption spectrometry and UV-visible spectrophotometric methods. Talanta 58, p.629-633.

RIZZO, A, C, L., LEITE, S, G (2004), Produção de sulfeto em reator do tipo UASB e sua potencial aplicação na remoção de metais pesados de efluentes. Rio de Janeiro: CETEM/MCT, 2004.

SANTOS, V. C. G.; TARLEY, C. R. T.; CAETANO, J.; DRAGUNSKI, D. C (2011), Copper ions adsorption from aqueous medium using the biosorbent sugarcane bagasse in natura and chemically modified. Water, Air, and Soil Pollution, Dordrecht, v. 216, n. 1/4, p. 351-359.

SRINATH, T., VERMA, T., RAMTEKE, P, W, GARG, S.K (2002), Chromium (VI) bios sorption and bioaccumulation by chromate resistant bacteria. Chemosphere 48, p.427435.

WOLFF, D, B (2005), Remoção Biológica de carbono e nitrogênio de esgoto urbano em reatores híbridos utilizando dois materiais suporte flotantes. Tese de Doutorado, Pós graduação em engenharia ambiental, UFSC, Florianópolis. 218 pag. 


\section{AGRADECIMENTOS}

Os autores agradecem a Fapemig, Projeto TEC - APQ-00920-11 pelo apoio financeiro. 